\title{
Normative and positive social work in the context of the placement decision: A defence of social workers
}

\author{
Kish Bhatti-Sinclair ${ }^{1}$ and Charles Sutcliffe ${ }^{2}$
}

\begin{abstract}
Two fundamental questions for social work are considered: one normative and one positive. First, is it possible for social work practice to be based on an objective that maximises social welfare; and second, does social work practice actually conform to some objective, which may or may not maximise social welfare? To shed light on these issues for social work we analyse them from the perspective of economics, in the context of one of the most important decisions involving social workers - placing children in out-of-home care. It is argued that deriving a societal objective faces formidable theoretical problems, and that even if a well-defined criterion was available, actual social work recommendations would still be inconsistent due to a lack of the requisite information and different interpretations of the available data. It is argued that the substantial empirical evidence from around the world on placing children out-of-home provides little evidence of consistent decision making. This may be because the statistical analyses have lacked the data and techniques necessary to detect the underlying patterns, or because placement decisions are largely random. The apparent absence of clear objectives, either specified by society or accepted custom and practice, places social workers in a very difficult position, making them open to press criticism and victimization, even though they acted entirely competently.
\end{abstract}

Keywords: social welfare; placement decision; statistical model; objective; press criticism

1. Reader in Social Policy and Social Work, University of Chichester

2. Professor of Finance, ICMA Centre, University of Reading

Address for correspondence: K.Bhatti-Sinclair@chi.ac.uk

Date of first (online) publication: 10th October 2019 


\section{Introduction}

This paper addresses two fundamental questions affecting social work by drawing on ideas from economics and the results of statistical investigations of the decisions in which social workers are involved. First, can social work practice be based on a set of societal objectives that maximise social welfare, that is the collective welfare of everyone in society, where individual preferences are aggregated in some way? Second, does childcare practice actually conform with a set of objectives, irrespective of whether these objectives maximise social welfare? Both of these questions are considered in the context of one of the most important decisions in which social workers are involved - the decision to place children in out-ofhome care - as a case study ${ }^{1}$. The conclusion on the first question is that there are very formidable difficulties in specifying welfare maximizing criteria for placing children in out-of-home care. Therefore, the criteria used to make this decision are arbitrary and may not lead to the best outcome for society. On the second question, an analysis of the empirical studies of placement decisions reveals both a lack of evidence of the application of a common set of criteria across the various samples studied, and the inability of the models to predict placement decisions with any accuracy, let alone the outcomes of placements. This is consistent with decision making that is not based on a common set of criteria. Finally, we consider the effects of this inability to specify the criteria for placing children, and the apparent inconsistency in placement criteria used in practice and on the behaviour of social workers. We argue that this situation, which is outside the control of individual social workers, has played an important role in creating the media victimization of social workers involved in some abuse and neglect cases. We propose that this victimization has influenced the behaviour of social workers in negative ways.

Section 1 considers the normative question of whether it is possible to specify a set of criteria for the placement decision that maximises social welfare, and Section 2 analyses the positive question of whether actual placement decisions conform with some set of criteria. Section 3 discusses the consequences of this inability of society to specify a clear welfare maximizing objective, and the lack of consistency in the actual decisions. Finally, Section 4 has our conclusions.

\section{Optimal placement decisions}

In order to make the best placement decisions, some criterion for what constitutes the best decision is needed, and this presents major difficulties. Decision makers in private companies generally have the objective of making a profit, and need only consider the effects on their company, that is just the private costs and benefits. Individuals make decisions that maximise their personal utility, which 
only includes the effects on others if such external effects affect their utility. Social workers are involved in decisions on behalf of society, and the very general objective for placing a child in care, taken from welfare economics, is to maximize social welfare. Such decisions have the potential to affect every member of society, however remote their connection to the decision. So, in order to participate in making the best decision for society, social workers need to know; not how they personally rank the alternative options, but how the effects of a decision are valued by each member of society. These individual valuations (or utilities) must then be aggregated in some way to produce a societal ranking of the alternatives. In theory this is done by inserting the individual valuations of a particular decision into a social welfare function - a concept introduced by Bergson (1938).

There is a large welfare economics literature dealing with the problem of aggregating individual preferences to make collective choices; but no generally accepted solution exists (for example, Sen, 1970). For example, in his famous 'impossibility theorem' Kenneth Arrow $(1950,1951)$ showed that no voting system exists for ranking alternatives which meets five very sensible axioms (transitivity, non-dictatorship, independence of irrelevant alternatives, Pareto optimality and unrestricted domain). In 1947 Winston Churchill said that

many forms of Government have been tried, and will be tried in this world of sin and woe. No one pretends that democracy is perfect or all-wise. Indeed it has been said that democracy is the worst form of Government, except for all those other forms that have been tried from time to time.

Churchill's view agrees with Arrow's impossibility theorem that one of the most widely accepted ways of making collective decisions (democracy) has serious flaws, and goes further in arguing that no better mechanism exists.

Despite the impossibility of specifying a set of decision criteria leading to the best outcome for society, society may somehow decide on a particular objective for use in the child placement decision, for example, the 'best interests of the child'2. But this raises further problems. The phrase 'best interests of the child' suggests that only the child's interests matter, and the interests of everyone else (for example, the child's parents and siblings, society) are disregarded (Charlow, 1987; Elster, 1987; and Salter, 2012), which conflicts with the concept of maximizing social welfare. Nevertheless, the concept of the 'best interests of the child' is enshrined in the UN Convention on the Rights of the Child (1989), and used by many counties as the paramount principle guiding placement and other decisions concerning children. The 'best interests of the child' is not a well-defined concept, and has been widely criticised as being vague and indeterminate (Charlow, 1987; Elster, 1987; Freeman, 2007; Kelly, 1997; Mnookin, 1975; Parker, 1994; Salter, 2012). Indeed, Salter (2012) recommended its rejection.

Four major problems with the 'best interests of the child' have been identified 
by Mnookin (1975), Elster (1987), Parker (1994) and Freeman (2007) - options, outcomes, values and probabilities. First, the set of available options or choices (for example, some form of placement) must be known, and this condition is usually satisfied. Second, the outcomes of each option must be predicted, which requires information on which to base these forecasts. For example, how long will a placement last, and how will it alter the child's personal relationships, educational attainment, and subsequent employment. Good information on which to base such predictions is generally lacking, and so the predictions will be inaccurate and potentially biased by the opinions of the forecaster ${ }^{3}$. Third, assuming the outcomes of each of the available options can be reliably predicted, there is the problem of aggregating the effects of the various outcomes, for example, the child's health, education, behaviour, and emotional development over their life, in order to choose the option which is in the 'best interests of the child'. Such aggregation requires incommensurable trade-offs and impossible judgements, for example, trading off a good education against excellent personal relationships.

Fourth, the outcomes from each option cannot be predicted with certainty, and so decision makers need to estimate probabilities for the various outcomes. Even if a substantial evidence base is available on the outcomes of the various options (for example, the effects of placing children in specified forms of care), there is still considerable uncertainty concerning the effects for a particular child. Not only is the future uncertain, but every situation is unique, and decision makers must use their judgement in forming expectations about the outcomes for a particular child, with different expectations for the same child based on the same evidence being entirely legitimate. For some placement decisions the outcomes may be reasonably predictable, while for others there may be considerable risk. For example, an institutional placement may be thought to have a more predictable outcome than leaving the child at home. If the high risk decision has higher expected benefits (for example, the child may flourish if left at home), there is a potential trade-off between risk and the expected benefits. The decision maker needs, in some unspecified way, to use societal risk preferences when making such trade-offs. This could be to maximise the social welfare associated with the worst possible outcome, that is the maximin, which has been proposed as a societal objective by Rawls (1999), and is used as the solution to game theory problems (for example, Owen, 1995). In this case the decision maker only needs to predict the worst outcome from each choice, not the probability distribution for all outcomes. However, this is a very risk averse approach. A more ambitious approach is to permit a trade-off between risk and expected benefits, as is standard in economics and the analysis of financial markets, where the risk of a bad outcome is accepted in exchange for the possibility of a much better outcome. However, specifying and applying this risk versus expected benefit trade-off for society is problematic.

There is a fifth problem with the 'best interests of the child' - resources; 
unmentioned by Mnookin (1975), Elster (1987), Parker (1994) and Freeman (2007). With limited resources, the placement of one child diverts resources away from other forms of child care, creating an inter-relationship (negative externality) between different child care decisions. Therefore, given scarce resources, choices must be made between children, and it may not be possible to pursue the best interests of every child, only those of selected children. To deal with this issue, the societal objective needs to become 'the best interests of all children', and this requires the co-ordination of all placement decisions, making the problem even more difficult.

As the above discussion shows, determining the best placement decision faces formidable difficulties. In the absence of a generally accepted societal objective which incorporates a way of forecasting and aggregating the different outcomes from an option, and which provides preferences for making risk-expected benefit trade-offs and choosing which children should receive care; constructing a normative model to give the best placement decisions for society is impossible. In the absence of such a normative model, decision makers may aggregate the various outcomes of a particular option in different ways, use a variety of preferences when making risk-benefit trade-offs, attach different probabilities to the outcomes of an option, and allocate scarce resources to different children. Therefore different decision makers may, quite sensibly and justifiably, make different decisions for the same child based on the same evidence, leading to different outcomes.

Since placement decisions must be made, society may amplify a flawed societal objective such as 'the best interests of the child' with various regulations and guidance. The criteria used by social workers and other professionals to make placement decisions include many factors, including compliance with international equal rights provisions such as the UN Convention on the Rights of the Child (1989). National guidance, such as Working Together to Safeguard Children (HM, Government 2018), is also important when making placement decisions. This stipulates that child protection is everyone's responsibility and contextual and environmental factors are critical to understanding the impact of decision making. This guidance uses the 'best interests of the child' as its paramount objective, mentioning the concept seven times; and details its application across 112 pages (HM Government, 2018). But a study of fifty decision makers led Banach (1998) to conclude that there is no universally recognized definition of the 'best interests of the child', and great variability in what is interpreted as the 'best interests of the child' when placing children. 


\section{Criteria used for actual placement decisions}

The previous section has argued that placement decisions cannot be based on a set of societal norms. In the absence of socially optimal placement criteria, the childcare system must somehow adopt a set of criteria and procedures to be used in practice. This section looks at the international evidence on the criteria actually used by professionals in making the placement decision, with the aim of uncovering the implicit criteria. To this end we adopt a revealed preference approach by investigating whether actual placement decisions reveal a set of objectives. Over the past fifty years there have been about one hundred empirical studies in English of the placement decision across nine countries ${ }^{4}$. Despite this large amount of empirical work, a consensus has not emerged on a set of factors which drive the placement decision, and enable it to be predicted or explained with a reasonable degree of accuracy (Bhatti-Sinclair and Sutcliffe, 2013). The statistical models explain only a small part of the variation in the placement decision, with the identity of the statistically significant explanatory variables changing from study to study. This situation can be explained in two very different ways:- (a) placement decisions are largely made at random, as suggested by Fanshel (1981), Fanshel and Shinn (1978, p. 506), Lindsey (2004), Runyan et al (1981) and Thoma (1998); or (b) placement decisions are not random, and there are reasons why the empirical studies have failed to detect an underlying set of criteria.

A major part of this debate of whether placement decisions are largely random revolves around the ability of statistical models to explain and predict the placement decision. This question has also been considered without recourse to statistical models. This concerns the education and training of social workers, and the information on which their recommendations are based. The statistical models of the placement decision will be considered first, followed by the issue of the education and training of social workers and the information available to them when making placement recommendations.

\section{Statistical models}

A statistical model which identifies variables that are strongly associated with the decision to place a child in care would be very useful for social workers. It would identify some of the variables (or their proxies) which the average professional is using when involved in placement decisions. This could then be checked for consistency with any available societal norms. Assuming the variables being used in practice are socially acceptable, they could be used to help identify and focus scarce resources on children at greatest risk of being placed, and in the training of those making this decision.

The first issue is the generally low explanatory and predictive power of the 
statistical models. The empirical studies only explain a small proportion of the insample variation in placement decisions, for example, the average $R^{2}$ value is $25 \%$ for the 18 studies that report an $\mathrm{R}^{2}$ (Bhatti-Sinclair and Sutcliffe, 2013)5. This lack of explanatory power has been maintained across time. Since the models generally explain only a small amount of the in-sample variability of the dependent variable, a very considerable amount of unexplained variation is left. In addition, the predictive ability of these models, as measured by classification tables, is also generally low.

A second issue is that the identity of the statistically significant explanatory variables changes between studies. While the many empirical studies have found a range of statistically significant explanatory variables, given large samples of many thousands of cases and well over thirty explanatory variables, finding a reasonable number of statistically significant explanatory variables in any particular study is not a surprise. The more important finding is that there is little uniformity between empirical studies in the identity of the explanatory variables that are statistically significant (Bhatti-Sinclair and Sutcliffe, 2013).

The third issue is the omission of relevant variables from the analysis, and the associated bias. Some key variables may not have been measured, and so are excluded from models. For example, only five empirical studies of the placement decision (Anderson, 2010; Freisthaler et al, 2007; Hiilamo, 2009; Lery, 2009; and Curtis and Alexander, 2010) have included neighbourhood effects, with the first four finding they had a modest effect on the placement decision. Only one study (Rapp, 1982) has included the effect of capacity constraints on the supply of outof-home places. There are many subtle differences between cases which are hard to record and include in empirical studies, and these could lead to different placement decisions. It is possible that social workers are picking up this unrecorded information and using it in their placement recommendations according to a common set of criteria, weights and forecasts, leading to consistent decisions. However, since statistical models are unable to incorporate this information because it is hard to measure and record in case files, the statistical models have low explanatory and predictive power.

It is also possible that different professionals are using the same information, decision criteria and associated weights, but have different expectations of the outcome from a particular placement, and so make different placement recommendations. Such heterogeneous expectations introduce additional noise into the modelling process, lowering both the explanatory power and significance levels of the explanatory variables. Expectations are difficult to incorporate in statistical models, and no empirical study of the placement decision has done this. The lack of consistency between studies in which variables are significant could also be due to the choice of the set of explanatory variables included in a model. There is a large number of potential explanatory variables (several hundred), not all of which can be included in a model. Unless the explanatory variables have zero correlation with the omitted variable, this leads to omitted variable bias which causes the 
estimated coefficients for the included explanatory variables to be biased. Finally, high correlations between the explanatory variables mean that a variable's statistical significance varies, depending on which other explanatory variables are included in the model. Thus variable $X$ may be significant only in the absence of variable $Y$.

The fourth issue concerns measurement problems. Some relevant variables are very hard to measure, for example, psychological and behavioural variables. In consequence, proxies have been constructed in a wide variety of ways; and this may mean a variable is significant in one study, but not in another. In addition, most studies have quantified some continuous variables as either zero or one, which could have a similar effect. Although the choice and measurement of the explanatory variables could have affected the results, there is little evidence that this is the case. Across about one hundred studies a wide range of explanatory variables measured in variety of ways has been investigated, and some researchers have used stepwise regression to automatically choose the set of explanatory variables ${ }^{6}$.

A fifth statistical issue is that inappropriate estimation techniques may have been used. A range of estimation techniques have been applied to the placement problem - logistic regression, discriminant analysis, probit analysis, and artificial neural networks. But there are other techniques such as random forests (Breiman, 2001) that have yet to be applied to this problem and they may prove more successful in unearthing a common set of variables which explain a substantial amount of insample variation. However, McDonald, et al (2001) and Bhatti-Sinclair and Sutcliffe (2012) applied both logistic regression and artificial neural networks to the same set of data and obtained similar results from these two different techniques, suggesting that a change of technique does not change the conclusions.

A sixth issue is that the wrong functional form has been used in the regressions, as some of the relationships may be non-linear and interactive, rather than linear and additive. However, previous studies have investigated interactive formulations, and a few have used artificial neural networks which automatically search for both non-linear and interactive effects.

The seventh statistical issue is that many empirical studies have analysed heterogenous samples. The placement problem is not a single problem, but many similar problems; while most empirical studies have analysed them as a single problem. As well as differences in the definition of the placed and non-placed children (for example, the non-placed children may be the general population, or they may be children for whom there is substantiated abuse or neglect), placement studies also differ by the area or country studied, and the time period over which the data was collected. It is also possible that the characteristics of parents and children vary with the primary reason for placement (Delfabbro et al, 2002). However, a number of studies have looked at homogeneous samples and at the primary reason for placement, and no consensus has emerged over the variables which explain the placement decision.

Finally, there is the issue of sample size. Although there have been about thirty 
empirical studies of the placement decision with more than 2,000 cases, the sample sizes used in some studies are very small making it difficult to obtain significant results.

\section{Other evidence}

In addition to the poor performance of the statistical models, there is further evidence consistent with the view that professionals make inconsistent placement recommendations. These findings are independent of any possible weaknesses in the regression-based studies discussed above.

Studies of simulated placement decision-making by experienced social workers show little agreement between the decisions made by different people, (DavidsonArad and Benbenishty, 2008, 2010; Kang and Poertner, 2006; Phillips et al, 1971; Rapp, 1982; Rossi, et al., 1999; Schuerman et al., 1999). Britner and Mossler (2002) found differences in the importance given to different types of information by the various groups of professionals involved in placement decisions. Again using vignettes, Keddell (2017) found that differences in risk aversion lead to different child welfare decisions. Since each participant in these studies was given exactly the same information on each case, the lack of consensus implies either that they are using different criteria, applying different weights to the same criteria, using different forecasts of the outcomes or different risk preferences. Their different decisions may be due to differences in their education, training and experience. So, while each worker may be using the same criteria and data, the placement decisions within a geographical area will be inconsistent. This view is consistent with the findings of Doyle (2008) who analysed for actual placement recommendations of professionals in Illinois. He showed that they differed in their propensity to place children, with some workers more likely to place children than others.

Different US states have very different placement rates (Lindsey, 2004). This may be due to differences in the demand and supply of placements between states, but it could also be due to differences in the criteria, weights and forecasts used by professionals in different states when making placement decisions. If the latter is true it implies that the same child would receive a different decision if located in another state, that is inconsistent decision making.

Social workers may be using unrecorded subtle information when making placement recommendations, relying on clinical judgement when performing assessments of child welfare. However, there is evidence that when performing assessments of child welfare, statistical models are superior to clinical judgement. Nisbett and Ross (1980, pp. 140-141) conclude that the predictions of human experts are inferior to those of statistical models, even if the experts have more data than the statistical model, and the model is sub-optimal. White and Walsh (2006) reviewed the empirical evidence which compared two different methods for 
risk assessment of child maltreatment - consensus based and statistically based instruments. Consensus-based instruments are compiled by experts who draw on their collective wisdom and experience, while statistically-based instruments rely on the conclusions of research based on empirical evidence to classify children. White and Walsh concluded that the statistically based approach is superior to consensus based instruments. A similar conclusion on the superiority of statistical models was reached by Shlonsky and Wagner (2005). If statistical models are superior to expert judgement, then reliance on clinical judgement may lead to inferior decisions, and quite possibly a lack of consistent decisions.

None of these arguments is conclusive, and conclusions must be based on the balance of probabilities. There is evidence consistent with the view that placement recommendations do not accord with a common set of criteria and are inconsistent both between individual workers and between geographical areas; and little evidence in favour of the alternative hypothesis that professionals are following a common set of decision criteria. This suggests that placement decisions may be close to random.

\section{Some implications}

This section considers some of the implications of the difficulties of making placement decisions, given the lack of clear well defined objective and well established professional practice. The placement decision, under Section 17 of the Children Act (1989), requires an assessment of whether a child is likely to suffer significant harm or not. This is a binary classification problem. A multi-agency child protection conference agrees parameters, time scales and the involvement of professionals and family members. All processes take account of the needs, wishes and feelings of the child. Multi-agency safeguarding partnerships (HM Government, 2018) include senior representatives from the local authority, health services and local police forces in the first instance. Legal proceedings require the appointment, in certain cases, of independent review officers (IRO), guardians ad litem and specialist law professionals who follow court rules. This increases the number of professionals involved, the level of scrutiny and the upholding of legal frameworks which leads, all too often, to delays in service provision such as care orders. The role of the IRO was created to improve the quality of service to children followed by a national protocol on information exchange, effective working and better communication between the agencies involved (Dickens, et al, October 2014).

Social workers lead the assessment process, with input from allied professionals such as the police, teachers and health staff. Social workers may correctly recommend not to place a child who will be unharmed at home, or to place a child who would otherwise be harmed at home. However, they may make incorrect 
classifications. A type 1 error is to decide to place a child who will not be harmed at home. This false positive leads to an unnecessary placement. A type 2 error occurs when a social worker does not place a child who will be harmed at home. This false negative means the child is left where she or he may suffer serious harm.

There is considerable risk when making the placement decision, even if excellent information is available. Therefore decisions (or classifications) that are ex post incorrect may be made due to the unpredictability of human behaviour, not the incompetence of the social worker. In some cases professionals may correctly predict that a child will be harmed at home, but be unable to place the child because the available evidence is insufficient to support such a decision. This leads to what appears to be a type 2 error, even though the social worker has made the correct diagnosis. Hollis and Howe (1987) conclude that workers are morally at fault when their placement recommendations turn out badly because, although 'accurate prognosis is usually impossible, .... moral risk goes with the job'. In other words, even though they followed the rules and were not incompetent or negligent, by choosing to work in child protection they have accepted responsibility for bad outcomes, for example, all type 2 errors. MacDonald (1990) has rejected this view, but it is consistent with the widespread blaming of social workers for bad outcomes.

Even for unexceptional cases, placing a child in care can often be an adversarial process leading to conflict between professionals acting on behalf of the state, and the child's family. In some cases placement leads to a highly negative outcome, which results in strong public condemnation. While placement decisions are made collectively by a group of professionals, it is the social workers who are publicly criticised, for example, the high profile deaths of Maria Colwell, Jasmine Beckford, Victoria Climbié, Peter Connelly and Daniel Pelka; and the Cleveland child abuse affair, (Ayre, 2001; Franklin, 1989; Franklin and Parton, 2001; Galilee, 2006; Warner, 2014). In contrast, correct placement decisions rarely produce spectacular and well publicised successes to offset the negative effects of type 2 errors.

Although other public servants face criticism for decisions that turn out badly, criticism is especially acute for social workers as 'decisions about the protection of children are among the most difficult that any professional group has to take' (Munro, 2011, p. 124) ${ }^{7}$. Franklin and Parton (2001) present an analysis of the column inches nine UK national newspapers devoted to social work in the period July 1997 to June 1998. Adverse comment accounted for 63\% of these reports, while beneficial comments were only 7\% - a ratio of nine to one. Reid and Misener (2001) analysed the headlines of social work stories in major UK and US newspapers on 20 random days in 1995-1999. Only 26\% of the US headlines were negative, while $80 \%$ of the UK headlines were negative, indicating that a hostile press for social work is a much bigger problem in the UK. Such criticism, which can verge on the victimization of individual workers, is often unjustified as their performance is judged on the basis of the unfavourable outcome; with minimal consideration of the difficult and unstructured nature of such decisions. Given the imperfect information and 
risks involved, as MacDonald (1990) has written, 'there will inevitably be negative outcomes from optimal decisions'.

Such public condemnation has led to the undesirable outcomes of defensive recommendations by social workers, for example, the use of the maximin criterion; and the introduction of bureaucratic rules to provide a defence when bad outcomes occur $^{8}$. For example, to avoid criticism for making type 2 errors, social workers may adopt a maximin objective and recommend placing more children in care than otherwise, diverting limited resources from other forms of care. Therefore some children do not receive the care they would otherwise have received.

The lack of good information and a clear objective requires social workers to use their discretion and judgement, not to mechanically follow a set of detailed rules. This discretion means workers are usually unable to defend themselves from criticism by arguing they followed explicit guidance or rules. This discretion has led to calls for more rules on placement recommendations allowing social workers not to be personally at fault when the outcome is unfavourable (Harris, 1987, Jack and Donnellan, 2013). Detailed rules for making these decisions would not lead to optimal decisions because, for the reasons given above, society cannot specify the socially optimal decision. Even if society could overcome this difficulty, every case is unique, with different decision makers justifiably coming to different conclusions on the same evidence. Therefore, while a set of rules could be devised, making socially optimal placement decisions is not susceptible to such mechanical decision making, and would probably lead to worse outcomes. (Ayre, 2001, Harris, 1987). Even if they follow detailed bureaucratic procedures and 'tick the boxes', social workers may be criticised. In 2008 David Cameron (leader of the Conservative Party) criticised Sharon Shoesmith (head of children's services at Haringey Council) for the death of Peter Connelly (Baby P), not because she failed to follow procedures, but because she did not use her common sense (Warner, 2014).

Commenting on the public criticism of social workers following unfavourable outcomes, the impossibility of ensuring only favourable outcomes and the use of detailed rules that are not necessarily in the 'best interests of the child'; Munro (2011, pp. 134-5) wrote that

the media and the public have a role to play in taking a more realistic view of the impossibility of eradicating all uncertainty from child protection. The false hope of eliminating risk has contributed significantly to the repeated use of increasing prescription as the solution to perceived problems. Consequently, this has increased defensive practice by professionals so that children and young people's best interests are not always at the heart of decisions. It is a major challenge to all involved in child protection to make the system less 'risk averse' and more 'risk sensible'. 


\section{Conclusions}

If society wants social workers to apply a common set of placement criteria to enable consistent placement recommendations across the system, these criteria must be explicitly specified. However, in answering the normative question of specifying placement criteria society faces formidable problems. The research of Kenneth Arrow and Amartya Sen indicates that specifying a set of criteria which maximises social welfare is impossible. Therefore any criteria used to make placement decisions are not necessarily the best for society, and a superior set of criteria may exist, but is unknowable. Assuming a set of criteria has somehow been specified by society, the problems of measuring and then aggregating the incommensurable dimensions of placement outcomes, forecasting placement outcomes, dealing with the risk of placement outcomes and deciding which children will be denied care due to a lack of resources remain. Therefore, even though society has specified a criterion (for example, the 'best interests of the child'), unless all discretion is removed, actual placement decisions will be inconsistent due to differences between professionals in how they forecast outcomes, aggregate the possible outcomes, allow for risk and make trade-offs between children needing care. In consequence, placement decisions are hard to defend as social workers make subjective judgements trying to satisfy woolly objectives.

The related positive question is the identification of the criteria used by those placing children, and whether a common set of criteria is actually being applied. These criteria may not be socially optimal, just what is done in practice. The use of a common set of criteria would ensure consistent placement recommendations, making it easier to make and defend particular decisions. However empirical studies have failed to find a common set of explanatory variables, implying there is little predictability in placement decisions, although it is impossible to prove conclusively that there is not some yet-to-be-discovered underlying logic to these decisions. The poor fit of the statistical models and their inconsistency from study to study may be due to a range of data and the statistical problems; with the implication that, if suitable data and statistical methodology were used, the performance of these models would improve and a common set of criteria emerge. However, since ideal data is unavailable, and undiscovered superior statistical techniques are unknown, this proposition is untestable. All that can be done is to show that, despite extensive searches, no such logic has yet been found. This view is supported by the poor agreement between social workers when faced with identical cases, the substantial variation in placement rates across the USA, and the evidence that statistical models are superior to clinical judgement for risk assessments.

Future statistical and other research into the placement problem may be able to identify some important explanatory variables, and this will probably require differentiating between different types of placement problem. Publication of such results may then change the behaviour of professionals, so that their decisions 
conform more closely with these results - a self-fulfilling prophecy. Another possibility is that society specifies more clearly the criteria to be used when placing children in care leading to consistency, although not necessarily optimality, in actual placement decisions.

The lack of clear objectives (either specified explicitly by society or derived from accepted custom and practice) means social workers are in a very difficult and exposed position. They are expected to make good recommendations without knowing the definition of a good decision, which makes them highly vulnerable to criticism. Their recommendations are based on forecasting the probabilities of different outcomes, and then aggregating the values individuals place on these incommensurable outcomes (after allowing for risk-expected return preferences), as well as deciding which children are denied care due to a lack of resources. The subjective nature of these decisions means different social workers can, quite legitimately, make different recommendations based on exactly the same information. When a placement decision has an unfortunate outcome the worker is unable to demonstrate that they complied with an accepted set of societal objectives and/or professional procedures. In the UK the press have attacked, and in some case victimised, individual social workers when decisions have turned out badly, even though the individual has acted competently. Criticism of the decisions made by such social workers needs to take account of the complex and challenging nature of such decision making.

\section{Notes}

1. We define the placement decision as placing a child in some form of out-of-home care, for example, foster care

2. The Children Act (1989) introduced the concept of 'significant harm', which provides a threshold for intervention in the best interests of the child

3. This problem is accentuated because the currently available information is constantly changing, offering a fast-moving picture of the situation

4. UK, USA, Canada, Sweden, Denmark, Israel, Netherlands, Australia and Norway

5. Measures of unexplained variation (for example, $R^{2}$ ) are problematic for estimation techniques such as logistic regression and discriminant analysis, and different studies have used different measures (Menard, 2010). Therefore, while the $R^{2}$ numbers are low, in some cases this could be due to problems in devising a suitable measure of explained variation in the dependent variable. However, while such measures may sometimes understate the explanatory power, they still give a reasonable approximation

6. Stepwise regression automatically selects the model with the highest probability of fitting the data by allowing the choice of the set of explanatory variables to be dictated by the data 
7. Additional reasons for the press victimizing social workers have also been proposed. These include: many newspapers being hostile to public services; the promise of protecting all children is impossible to deliver; the use of generalist reporters with little understanding of social work; child abuse makes good copy, newspaper staff are mostly male, while about three quarters of social workers are female (Franklin and Parton, 2001; Ayre, 2001, Fry, 1991)

8. Other undesirable outcomes include a drop in staff morale, increased staff absences, recruitment and retention problems, lower pubic respect for staff, and the verbal abuse of staff (Galilee, 2006; Elsley, 2010).

\section{References}

Andersen, S.H. (2010) A Good Place to Live? On Municipality Characteristics and Children's Placement Risk, Social Services Review, 84, 2, 201-224

Arrow, K.J. (1950) A Difficulty in the Concept of Social Welfare, Journal of Political Economy, $8,4,328-346$

Arrow, K.J. (1951) Social Choice and Individual Values. Chichester: Wiley

Ayre, P. (2001) Child Protection and the Media: Lessons from the Last Three Decades, British Journal of Social Work, 31, 6, 887-901

Banach, M. (1998) The Best Interests of the Child: Decision-Making Factors, Families in Society: The Journal of Contemporary Human Services, 79, 3, 331-340

Davidson-Arad, B. and Benbenishty, R. (2008) The Role of Workers' Attitudes and Parent and Child Wishes in Child Protection Workers' Assessments and Recommendation Regarding Removal and Reunification, Children and Youth Services Review, 30, 1, 107-121

Davidson-Arad, B. and Benbenishty, R. (2010) Contribution of Child Protection Workers' Attitudes to their Risk Assessments and Intervention Recommendations: A Study in Israel, Health and Social Care in the Community, 18, 1, 1-9

Bergson, A. (1938) Reformulation of Certain Aspects of Welfare Economics, Quarterly Journal of Economics, 52, 2, 310-334

Bhatti-Sinclair, K. and Sutcliffe, C. (2012) What Determines the Out-of-Home Placement of Children in the USA?, Children and Youth Services Review, 34, 9, 1749-1755

Bhatti-Sinclair, K. and Sutcliffe, C. (2013) Challenges in Identifying Factors Which Determine the Placement of Children in Care? An International Review, Child and Adolescent Social Work Journal, vol.30, 4, 345-363

Breiman, L. (2001) Random Forests, Machine Learning, 45, 1, 5-32

Britner, P.A. and Mossler, D.G. (2002) Professionals' Decision-Making About Out-of-Home Placements Following Instances of Child Abuse, Child Abuse and Neglect, 26, 4, 317-332 Charlow, A. (1987) Awarding Custody: The Best Interests of the Child and Other Fictions, Yale Law and Policy Review, 5, 2, 267-290

Curtis, C.M. and Alexander, R. (2010) Correlates of African American Children In and Out 
of Their Families, Families in Society, 91, 1, 85-90

Delfabbro, P.H., Barber, J.G. and Cooper, L. (2002) Children Entering Out-of-Home Care in South Australia: Baseline Analyses for a 3-Year Longitudinal Study, Children and Youth Services Review, 24, 12, 917-932

Dickens, J., Schofield, G., Beckett, C., Phillip, G., and Young, J. (2014), Care Planning and the Role of the Independent Reviewing Officer. Research Briefing, Centre for Research on Children and Families, University of East Anglia, www.uea.ac.uk/centre-research-child-family

Doyle, J.J. (2008) Child Protection and Adult Crime: Using Investigator Assignment to Estimate Causal Effects of Foster Care, Journal of Political Economy, 116, 4, 746-770

Elsley, S. (2010) Media Coverage of Child Deaths in the UK: The Impact of Baby P: A Case of Influence?, Briefing no. 8, University of Edinburgh/NSPCC, June

Elster, J. (1987) Solomonic Judgements: Against the Best Interest of the Child, University of Chicago Law School, 54, 2, 1-45

Fanshel, D. (1981) Decision Making Under Uncertainty: Foster Care for Abused or Neglected Children?, American Journal of Public Health, 71, 7, 685-686

Franklin, B. (1989) Wimps and Bullies: Press Reporting of Child Abuse. In Social Work and Social Welfare, edited by P. Carter, T. Jeffs and M. Smith, Open University Press, 1-14

Franklin, B. and Parton, N. (2001) Press Ganged! Media Reporting of Social Work and Child Abuse. in M. May, R. Page and E. Brunsdon (Eds.) Understanding Social Problems - Issues in Social Policy. Oxford: Blackwell (pp.233-247)

Fry, A. (1991) Reporting Social Work: A View from the Newsroom. in M. May, R. Page and E. Brunsdon(Eds.) Social Work, the Media and Public Relations. Abingdon: Routledge (pp.63-75)

Fanshel, D. and Shinn, E. (1978) Children in Foster Care: A Longitudinal Investigation. New York: Columbia University Press

Freeman, M. (2007) Article 3. The Best Interests of the Child. in A. Allen, J.V. Lanotte, E. Verhellen, F. Ang, E. Berghmans and M. Verheyd (Eds.) A Commentary on the United Nations Convention on the Rights of the Child. Leiden: Martinus Nijhoff,

Freisthaler, B., Gruenwald, P.J., Remer, L.G., Lery, B. and Needell, B. (2007) Exploring the Spatial Dynamics of Alcohol Outlets and Child Protective Services Referrals, Substantiations and Foster Care Entries, Child Maltreatment, 12, 2, 114-124

Galilee, J. (2006) Literature Review on Media Representations of Social Work and Social Workers. Edinburgh: Scottish Executive

Harris, N. (1987) Defensive Social Work, British Journal of Social Work, 17, 1, 61-69

HM Government (1989) Children Act 1989

HM Government (2018) Working Together to Safeguard Children: A Guide to Inter-agency Working to Safeguard and Promote the Welfare of Children, July

Hiilamo, H. (2009) What Could Explain the Dramatic Rise in Out-of-Home Placement in Finland in the 1990s and Early 2000s?, Children and Youth Services Review, 31, 2, 177-184 Hollis, M. and Howe, D. (1987) Moral Risks in Social Work, Journal of Applied Philosophy, $4,2,123-133$

Jack, G. and Donnellan, H. (2013) Social Work with Children.Basingstoke: Palgrave 
Kang, H.A. and Poertner, J. (2006) Inter-Rater Reliability of the Illinois Structured Decision Support Protocol, Child Abuse and Neglect, 30, 6, 679-689

Keddell, E. (2017) Comparing Risk-Averse and Risk-Friendly Practitioners in Child Welfare Decision-Making: A Mixed Methods Study, Journal of Social Work Practice, 31, 4, 411-429

Kelly, J. (1997) The Best Interests of the Child: A Concept in Search of Meaning, Family and Conciliation Courts Review, 35, 4, 377-387

Lery, B. (2009) Neighbourhood Structure and Foster Care Entry Risk: The Role of Spatial Scale in Defining Neighbourhoods, Children and Youth Services Review, 31, 3, 331-337

Lindsey, D. (2004) The Welfare of Children. (2nd ed.) Oxford: Oxford University Press

MacDonald, G. (1990) Allocating Blame in Social Work, British Journal of Social Work, 20, $6,525-546$

McDonald, T.P., Poertner, J. and Harris, G. (2001) Predicting Placement in Foster Care: A Comparison of Logistic Regression and Neural Network Analysis, Journal of Social Service Research, 28, 2, 1-20

Menard, S. (2010) Logistic Regression: From Introductory to Advanced Concepts and Applications. London: Sage

Mnookin, R. H. (1975) Child-Custody Adjudication: Judicial Functions in the Face of Indeterminacy, Law and Contemporary Problems, 39, 3, 226-293

Munro, E. (2011) The Munro Review of Child Protection: Final Report. Department for Education, 173 pages

Nisbett, R. and Ross, L. (1980) Human Inference: Strategies and Shortcomings of Social Judgement, Prentice-Hall Inc

Owen, G. (1995) Game Theory, Third edition, Academic Press

Parker, S. (1994) The Best Interests of the Child - Principles and Problems, International Journal of Law and the Family, 8, 1, 26-41

Phillips, M.H., Shyne, A.W., Sherman, E.A. and Harding, B.L. (1971) Factors Associated With Placement Decisions in Child Welfare, Child Welfare League of America

Rapp, C.A. (1982) Effect of the Availability of Family Support Services on Decisions About Child Placement, Social Work Research and Abstracts, 18, 1, 21-27

Rawls, J. (1999) A Theory of Justice, Second edition, Oxford University Press

Reid, W.J. and Misener, E. (2001) Social Work in the Press: A Cross-national Study, International Journal of Social Work, 10, 3, July, 194-201

Rossi, P.H., Schuerman, J, and Budde, S. (1999) Understanding Decisions About Child Maltreatment, Evaluation Review, 23, 6, 579-598

Runyan, D.K., Gould, C.L., Trost, D.C. and Loda, F.A. (1981) Determinants of Foster Care Placement for the Maltreated Child, American Journal of Public Health, 71, 7, July, 706-711

Salter, E.K. (2012) Deciding for a Child: A Comprehensive Analysis of the Best Interest Standard, Theoretical Medicine and Bioethics, 33, 3, June, 179-198

Schuerman, J., Rossi, P.H. and Budde, S. (1999) Decisions on Placement and Family Preservation, Evaluation Review, 23, 6, 599-618

Sen, A.K. (1970) Collective Choice and Social Welfare, Holden-Day

Shlonsky, A. and Wagner, D. (2005) The Next Step: Integrating Actuarial Risk Assessment 
and Clinical Judgement into an Evidence-Based Practice Framework in CPS Case Management, Children and Youth Services Review, 27, 4, 409-427

Thoma, E. (1998) If You Lived Here, You'd Be Home Now - The Business of Foster Care, Issues in Child Abuse Accusations, 10

United Nations (1989) Convention on the Rights of the Child, UNICEF, 14 pages

Warner, J. (2014) 'Heads Must Roll'? Emotional Politics, the Press and the Death of Baby P, British Journal of Social Work, 44, 6, 1637-1653

White, A. and Walsh, P. (2006) Risk Assessment in Child Welfare: An Issues Paper, Centre for Parenting and Research, NSW Department of Community Services, September 